\title{
Akt2 Deficiency is Associated with Anxiety and Depressive Behavior in Mice
}

\author{
Christina Leibrock ${ }^{\mathrm{a}, \mathrm{c}}$ Teresa F. Ackermann ${ }^{\mathrm{a}, \mathrm{c}}$ Michael Hierlmeier ${ }^{\mathrm{a}}$ Florian Lang ${ }^{\mathrm{a}}$ \\ Stefan Borgwardt ${ }^{\mathrm{b}} \quad$ Undine E. Lang ${ }^{\mathrm{b}}$ \\ aDepartment of Physiology I, University of Tuebingen, Germany; ${ }^{b}$ Universitary Psychiatric Clinics (UPK), \\ University of Basel, Switzerland; cboth authors contributed equally to the paper
}

\author{
Key Words \\ Anxiety • Behavior • Depression • Akt2 $・ \mathrm{PI} 3 \mathrm{~K} \cdot \mathrm{GSK} 3 \cdot \mathrm{BDNF}$
}

\begin{abstract}
Background: The economic burden associated with major depressive disorder and anxiety disorders render both disorders the most common and debilitating psychiatric illnesses. To date, the exact cellular and molecular mechanisms underlying the pathophysiology, successful treatment and prevention of these highly associated disorders have not been identified. Akt2 is a key protein in the phosphatidylinositide-3 (PI3K) / glycogen synthase 3 kinase (GSK3) signaling pathway, which in turn is involved in brain-derived neurotrophic factor (BDNF) effects on fear memory, mood stabilisation and action of several antidepressant drugs. The present study thus explored the impact of Akt2 on behaviour of mice. Methods: Behavioural studies (Open-Field, Light-Dark box, O-Maze, Forced Swimming Test, Emergence Test, Object Exploration Test, Morris Water Maze, Radial Maze) have been performed with Akt2 knockout mice $\left(a k t^{-}\right)$and corresponding wild type mice $\left(a k t^{+/+}\right)$. Results: Anxiety and depressive behavior was significantly higher in $a \mathrm{kt}^{-/}$than in $a k t^{+/+}$mice. The $a k t^{-/}$mice were cognitively unimpaired but displayed increased anxiety in several behavioral tests (O-Maze test, Light-Dark box, Open Field test). Moreover, akt ${ }^{-/}$mice spent more time floating in the Forced Swimming test, which is a classical feature of experimental depression. Conclusion: Akt2 might be a key factor in the pathophysiology of depression and anxiety.
\end{abstract}

Copyright (C) 2013 S. Karger AG, Basel

\section{Introduction}

Phosphatidylinositide-3 kinase (PI3K) dependent signaling participates in the regulation of several fundamental neuronal processes, including neuronal growth, survival and differentiation, formation of dendrites as well as synaptic plasticity [1]. 
PI3K signaling is triggered by a variety of growth factors including brain-derived neurotrophic factor (BDNF) [2, 3], which has been implicated in bipolar disorder, depression, depression-related personality traits and anxiety [2,4-7]. Decreased expression of BDNF contributes to stress-related mood disorders and the upregulation of BDNF plays a role in the actions of different antidepressant treatments $[8,9]$.

Downstream targets of the PI3K include phosphoinositide dependent kinases and Akt $[3,10]$. Akt phosphorylates and thus inhibits glycogen synthase 3 (GSK3). PI3K-Akt signaling has been discussed to mediate antidepressant effects and constitutes an important signaling pathway in the subcellular integration of synaptic neurotransmission $[11,12]$. This pathway also modulates neuronal cell proliferation, migration, and plasticity [12]. Lithium, valproate, olanzapine and clozapine are at least in part effective via PI3K-Akt signalling [13-16]. Moreover, PI3K is involved in behavioral sensitization to cocaine [17], the extinction of fearful memories [18] and hippocampal plasticity [18]. Disruption of GSK3 phosphorylation by Akt decreases anxiety and reduces proneness to depression in mice [19]. Conversely, decreased expression of phosphoinositide dependent kinase 1 (PDK1), leads to increased anxiety [20].

The three Akt isoforms do not serve identical functions [21] Akt1 participates in the regulation of body and cell size $[22,23]$ and has been implicated in bipolar disorders [2427]. Akt3 participates in the signaling underlying developmental brain malformations [2832]. Akt2 is particularly important for glucose metabolism [33, 34] and participates in the regulation of neuronal differentiation and survival $[21,35,36]$ and dopamine transporter cell surface expression [37]. To the best of our knowledge, however, nothing is known about a role of Akt2 in the regulation of behavior and mood.

The present study thus aimed to define the role of the isoform Akt2 in mouse behavior. To this end, behavioral studies have been performed in Akt2 knockout (Akt2-/-) and wild type mice $(a k t+/+)$.

\section{Animals and Methods}

\section{Animals}

The generation, properties and genotyping of Akt2 deficient mice were described earlier [33]. Sex and age matched mice with age more than 2 months were used for the experiments. All animal experiments were conducted according to the German law for the care and use of laboratory animals and were approved by local authorities. For the present study $59 \mathrm{Akt} 2$ knockout mice (akt2 $\left.{ }^{-/}\right)$and 64 wild type mice $\left(a k t^{+/+}\right)$ were used. The akt2\% and akt2 ${ }^{+/+}$mice were divided into four sets (first set: $14 \mathrm{akt2 \%}, 16 \mathrm{akt} 2^{+/+}$mice, second set: $8 \mathrm{akt2 \%}, 10 \mathrm{akt} 2^{+/+}$mice, third set: $12 \mathrm{akt} 2^{\%}, 12 \mathrm{akt} 2^{+/+}$mice and fourth set: $4 \mathrm{akt2} \%, 5 \mathrm{akt} 2^{+/+}$ mice) and tested consecutively at an interval of four months. In the radial maze $12 \mathrm{akt} 2 \%$ and 11 akt $2^{+/+}$mice were tested. For the Morris Water Maze $9 \mathrm{akt} \%$ and $10 \mathrm{akt} 2^{+/+}$mice were used. Age at the beginning of the tests was 8-12 weeks.

\section{Housing and handling}

Mice were bred and housed in Tuebingen. They had access to a standard mouse chow and tap water ad libitum and were maintained at a 12:12 h inverted cycle with lights on between 7 p.m. and 7 a.m. Behavioral testing occurred between 8 a.m. and 8 p.m. Only one type of experiment was done on the same day and the home cage rack was brought to the test room at least $30 \mathrm{~min}$ before each experiment. Dry surfaces of apparatus were thoroughly cleaned with $70 \%$ ethanol before releasing the animal. Experiments extended over a total of 3 months and were done in the following order: open-field, light dark (LD) box, 0-maze, forced swimming test, emergence test, novel object. In addition, a further cohort of mice was tested on the 8-arm radial maze and another group on the Morris Water Maze.

Video tracking and illumination

For data acquisition animals were video tracked by the camera 302050-SW-KIT-2-CAM at a resolution of 0.62 to 0.72 pixel (TSE-Systems, Bad Homburg, Germany), Raw data were transferred to Excel for further analysis. Experiments were performed with diffuse indirect room light produced by dimmable bulbs, 
Leibrock et al.: Akt2 Impacts on Anxiety and Depression

adjusted to yield less than 30 lux in the center of the experimental arena. The only exception was the LD-box test where full room light was switched on to obtain approximately 500 lux in the lit chamber.

\section{Open-Field}

The quadratic arena had side lengths of $50 \mathrm{~cm}$, a white plastic floor and $40 \mathrm{~cm}$ high sidewalls. Each subject was released near the wall and observed for $30 \mathrm{~min}$. For evaluation, a border with $10 \mathrm{~cm}$ distance to the wall was considered. The layout is illustrated in Fig. 1A. Data were collected in the entire arena which was further divided into border- and center area. Corners as a subsegment of the border area were studied seperately. Global distance and speed as well as distance and time spent in the different regions were assessed. In addition the number of crosses over the lines of the virtual grid drawn on the arena surface were counted (horizontal activity). A frame generating a photoelectric barrier in the Open Field arena allowed the registration of rearings (vertical activity). Since some of the mice showed low numbers of rearings but long overall rearing times we also provide the rearing time normalized to the number of rearings (ratio time/rearing) indicating the average time for a single rearing.

Light-Dark (LD-) box

An infrared permeable box made of black acryl ( $40 \mathrm{~cm}$ high) was inserted into the Open Field arena and covered 33\% of the surface area (Fig. 2A). An aperture of $10 \mathrm{~cm}$ length and $11 \mathrm{~cm}$ height with rounded down corners led from the lighted arena to the dark box. The experiment was performed under direct room light. Each subject was released in the corner of the lit compartment and observed for $10 \mathrm{~min}$. The illuminated part of the arena was divided in subregions as well. As shown in the ground plan in Fig. 2A, data were also collected for corners and the entrance area of the box. Gathered were time spent in the different regions and covered distances as well as the number of transitions between lit chamber and dark box. Rearings were counted by the same photoelectric barrier used in the Open Field experiment.

\section{O-Maze}

A $5.5 \mathrm{~cm}$ wide annular runway was constructed using grey polyvinyl-chloride. It had an outer diameter of $46 \mathrm{~cm}$ and was placed $40 \mathrm{~cm}$ above the floor. The two opposing $90^{\circ}$ closed sectors were protected by $11 \mathrm{~cm}$ high inner and outer walls of grey polyvinyl-chloride, while the remaining two open sectors had a border of $5 \mathrm{~mm}$. Animals were released in one of the closed sectors and observed for $10 \mathrm{~min}$. A photograph illustrates the experimental set-up in Fig. 3A. The mice were not only confronted with open space, but also with height. After an acclimatization period mice advance onto an unprotected runway and dip their heads to explore the cliff. This behavior was classified as protected headdip when the body was still in the protected zone. When the protected zone was left completely the exploration of the hight was classified as unprotected headdip. Assessed were the numbers of protected and unprotected headdips, time and covered distance in protected and unprotected zones and the number of transitions between the areas.

\section{Forced Swimming Test}

In the Forced SwimmingTest mice were placed in a container filled with water of temperatures between 24 and $26^{\circ} \mathrm{C}$ (Fig. 4A). The diameter of the container was $20 \mathrm{~cm}$. The mouse was placed in the water without being able to touch the ground. Mice were observed during 6 min and the time they spent without movement, called floating, was recorded.

\section{Emergence Test}

For the Emergence Test, the procedure was modified after Dulawa et al. [21]. An infrared permeable box, which was previously in the home cage of the mouse during more than 24 hours, was inserted into the arena. The home box had a base area of 9x10 cm with two apertures $(3 \mathrm{~cm}$ length, $3.5 \mathrm{~cm}$ height with rounded down corners) on the long sides. The mouse was observed for $30 \mathrm{~min}$. A diagram shows the experimental setup in Fig. 5 A. The time, which the mice spent in their homebox and the number of entries into the open arena were recorded.

\section{Object Exploration Test}

For the object exploration test, the procedure was modified after Dulawa et al. [21]. The Arena was the same as for the Open Field and the Emergence Test. The mouse was first observed for 30min in the Open 
Leibrock et al.: Akt2 Impacts on Anxiety and Depression

Field arena. During that time mice became familiar with their environment. Afterwards, a falcon tube was additionally put into the arena and fixed with adhesive tape. Thereby the animals were confronted with a novel stimulus while offering the option to retreat into a familiar, safe area. The mice were then observed for another $30 \mathrm{~min}$ and the contact with the nose on the falcon tube was taken as criterion to analyze the reaction on a novel object. Figure 6A shows the layout of the arena. The number of approaches and the average distance to the novel object were determined.

\section{Morris Water Maze}

We adapted the original procedure for the use with mice [38, 39]. A round grey poly-propylene swimming tank with a diameter of $150 \mathrm{~cm}$ was filled with water (temperature $24-26^{\circ} \mathrm{C}$, depth $15 \mathrm{~cm}$ ) that was made opaque by addition of a white dye. The white round goal platform $(\mathrm{d}=12 \mathrm{~cm})$ was hidden $0.5 \mathrm{~cm}$ below the water surface. Salient distant cues such as wall-mounted laboratory shelves and various posters were available in room. Animals performed 30 training trials, 6 per day with intertrial intervals of 30-60min and pseudo-randomly varying starting positions. To minimize handling, they were transferred to the pool using a white plastic cup. The trials lasted until the mice climbed onto the platform or until 120s had elapsed. After they had reached the platform and stayed on it for five seconds they were allowed to climb onto a wire mesh grid and were transferred to their cage without further handling. During the first 18 trials (acquisition phase) the hidden platform was held in the same position and then moved to the opposite quadrant for the remaining 12 trials (reversal phase). Time and distance needed to complete the task, the time spent in the border area and the average swim velocity were recorded.

\section{Radial Maze}

The apparatus was constructed of grey poly-vinyl chloride with smooth surface and clear Perspex side walls. Eight arms $(7 \times 38 \mathrm{~cm})$ extended from the octagonal centre platform (diameter $18.5 \mathrm{~cm}$ ) with a $47 \mathrm{~cm}$ distance from the platform centre to the end of each arm. The maze was elevated $38 \mathrm{~cm}$ from the floor and placed in a room which was rich in salient extramaze cues. Baits were small single millet pellets and placed in submerged small metal cups at the end of each arm. Firstly dietary restriction over 2 days was carried out, which led to an $85 \%$ decrease of free-feeding body weight in all subjects. For two days habituation sessions followed, where all mice had the opportunity to collect several pellets in each baiting cup over a time period of 10 minutes. In the following ten days training sessions were carried out, where every mouse had to explore the maze and to collect food until it had consumed all pellets or 15 minutes had elapsed. Assessed were the number of correct choices until the first error was made (arm entries with pellet consumption), the total number of errors (entries to arms without pellet consumption), working memory errors (re-entries to arms where the pellet has already been consumed) and time as well as distance required to complete the task.

\section{Statistical analysis}

For the comparison of the test results of the $a k t 2^{\%}$ and $a k t 2^{+/+}$mice the statistic software Graph Pad Prism was used. Only results with $\mathrm{P}<0.05$ were considered significant.

\section{Results}

\section{Open-field}

In the open-field akt2\% mice showed the same speed as the akt2 ${ }^{+/+}$mice (Fig. 1B). However, the total distance traveled (Fig. 1C) was significantly decreased in akt2\% mice when compared to akt2 $2^{+/}$mice. The akt2\% mice also spent more time in the border area (Fig. 1D) and travelled a shorter distance there (Fig. 1E). Also the time the akt $\%$ mice spent

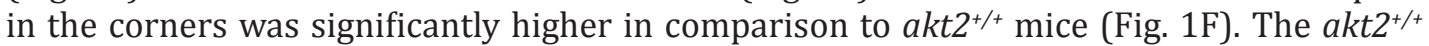
mice visited the center area more often, spent more time there and consequently travelled a longer distance in the center (Fig. 1G-I). Rearing behavior is shown in Table 1. 
A

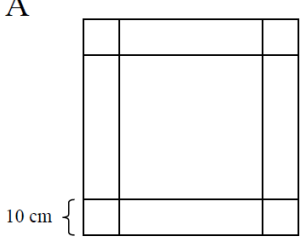

D

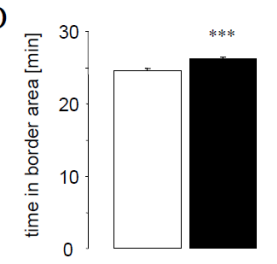

G

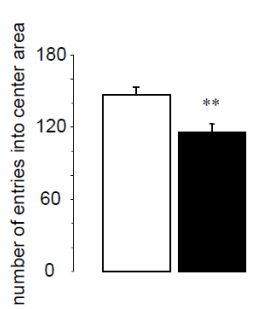

B

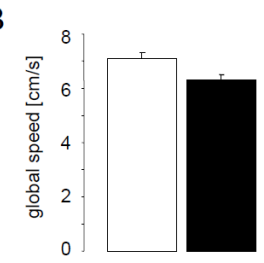

$\mathrm{E}$

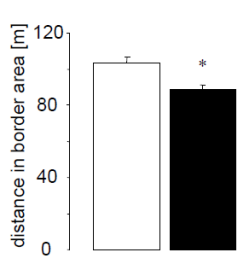

$\mathrm{H}$

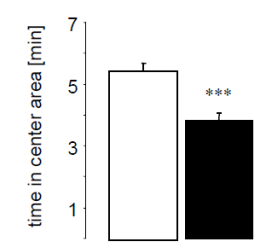

C

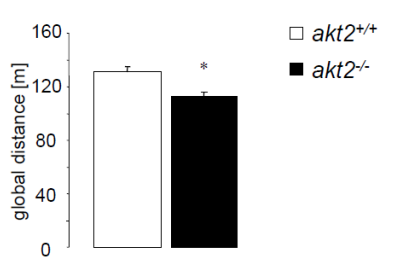

F

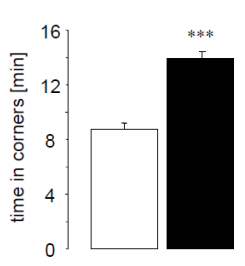

I

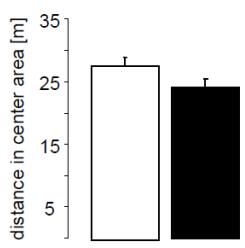

Fig. 1. Analysis of behavior in the Open Field Test. A: Layout of the Open Field arena. B: Average speed measured in the whole observation area. C: Total distance travelled during the observation time. D: Time spent in the border area of the Open Field arena. E: Distance travelled in the border area. F: Time spent in the corners of the Open Field arena. G: Number of visits to the center area. H: Distance travelled in the center area. I: Time spent in the center area.

Table 1. Synopsis of rearing parameters in the open field test (arithmetic means \pm SEM) of akt2-/- and akt2+/+ mice

\begin{tabular}{lccc}
\hline Open Field & akt2 ++ mice & akt2 $/$ - mice & Statistics \\
\hline Number of rearings in border area & $303.09 \pm 6.00$ & $277.11 \pm 8.37$ & $\mathrm{P}=0.0092 ;$ Mann-Whitney Test \\
Rearing time in border area (min) & $16.51 \pm 0.40$ & $12.60 \pm 0.48$ & $\mathrm{P}<0.0001 ; \mathrm{t}$-test \\
Ratio time/rearing in border area (s/rearing) & $3.33 \pm 0.11$ & $2.74 \pm 0.09 \quad \mathrm{P}=0.0003$; Mann-Whitney Test \\
Number of rearings in center area & $82.30 \pm 4.42$ & $52.92 \pm 4.72$ & $\mathrm{P}<0.0001 ; \mathrm{t}$-test \\
Rearing time in center area (min) & $3.08 \pm 0.18$ & $1.79 \pm 0.19$ & $\mathrm{P}<0.0001 ; \mathrm{t}$-test \\
Ratio time/rearing in center area (s/rearing) & $2.34 \pm 0.10$ & $1.93 \pm 0.09$ & $\mathrm{P}=0.0060 ; \mathrm{t}$-test
\end{tabular}

\section{Light Dark Box}

The $a k t 2 \%$ mice spent significantly more time in the hidden area than the $a k t 2^{+/+}$mice (Fig. 2B) and visited the hidden area more often (Fig. 2C). They also showed less rearing behavior indicated by a lower number of rearings (Fig. 2D) in the light area, a shorter rearing time (Fig. 2E) and a smaller ratio of number/time rearing (Fig. 2F). Despite the fact that the $a k t 2 \%$ mice spent more time in the dark area the number of rearings in the hidden zone (Fig. $2 \mathrm{G}$ ) was still decreased in comparison to $a k t 2^{+/+}$mice. The rearing time was almost the same in both groups (Fig. $2 \mathrm{H}$ ) which consequently leads to an increased ratio of time/number of rearings (Fig. 2I). 


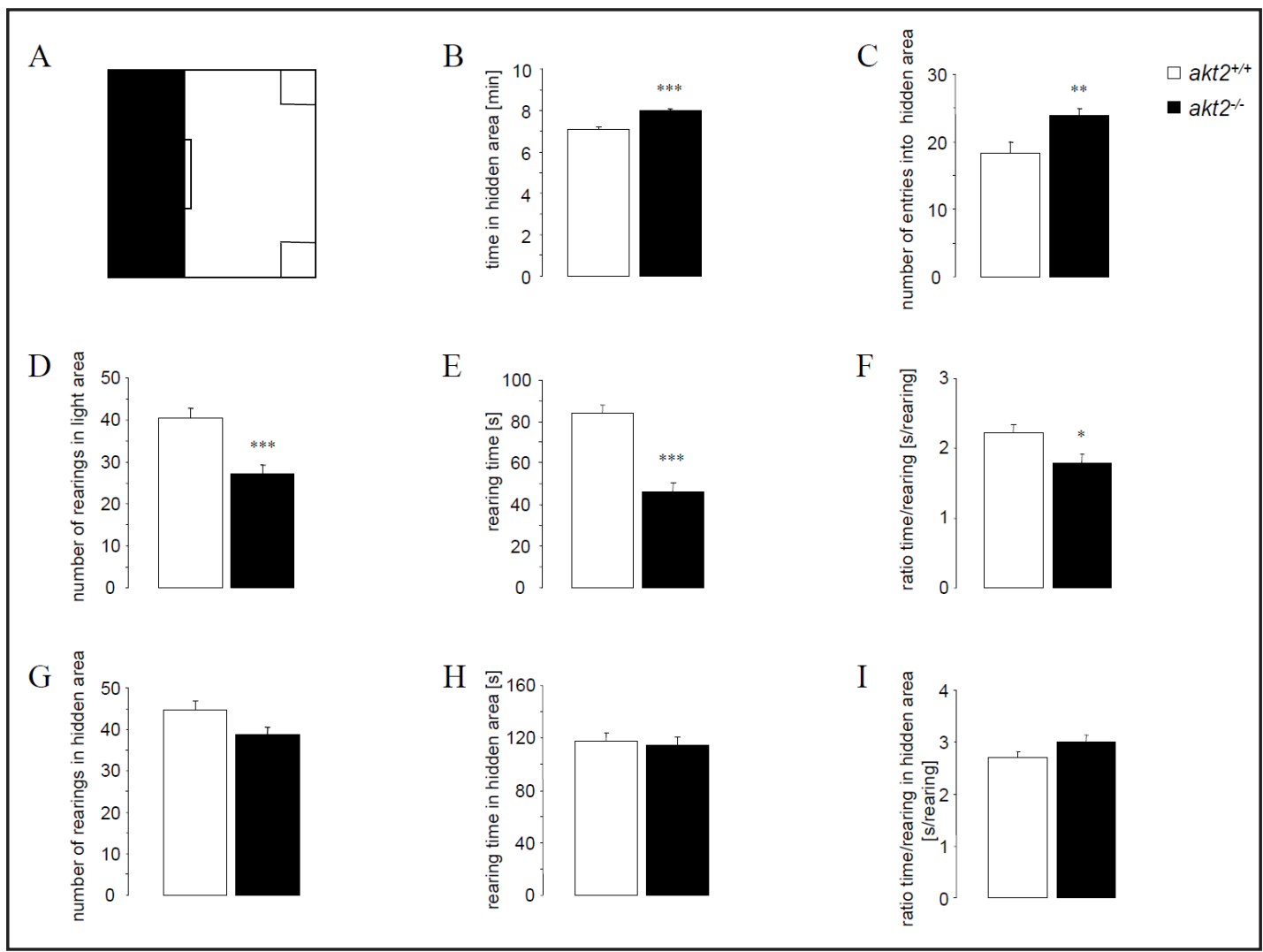

Fig. 2. Analysis of behavior in the Light Dark Box. A: Layout of the Light Dark Box. B: Time spent in the hidden area of the Light Dark Box arena. C: Number of visits to the hidden area. D: Number of rearings in the light area. E: Average rearing time in the light area. F: Ratio of the average rearing time and the number of rearings in the light area. G: Number of rearings in the hidden area. H: Average rearing time in the hidden area. I: Ratio of the average rearing time and the number of rearings in the hidden area.

Table 2. Synopsis of behavioral parameters in the Light Dark Box test (arithmetic means \pm SEM) of akt2-/- and akt2+/+ mice.

\begin{tabular}{|c|c|c|c|}
\hline Light Dark Box & akt $2+/+$ mice & akt2 $/-$ mice & Statistics \\
\hline Time in light area (min) & $2.89 \pm 0.10$ & $2.01 \pm 0.11$ & $\mathrm{P}<0.0001 ;$ t-test \\
\hline Distance in light area (min) & $22.49 \pm 1.12$ & $16.75 \pm 1.00$ & $P=0.0004 ;$ t-test \\
\hline Number of rearings in light area & $40.42 \pm 2.47$ & $27.03 \pm 2.23$ & $P=0.0002 ;$ t-test \\
\hline Distance in entrance area $(\mathrm{cm})$ & $136.67 \pm 7.53$ & $169.52 \pm 9.15$ & $P=0.0067 ;$ t-test \\
\hline Number of visits in entrance area & $21.42 \pm 1.27$ & $30.48 \pm 1.31$ & $\mathrm{P}<0.0001$; t-test \\
\hline Number of rearings in entrance area & $3.79 \pm 0.54$ & $3.74 \pm 0.62$ & $P=0.9540$; n.s.; t-test \\
\hline Rearing time in entrance area (s) & $6.89 \pm 1.03$ & $7.38 \pm 1.21$ & $P=0.7572 ;$ n.s.; t-test \\
\hline Ratio time/rearing in entrance area & $1.66 \pm 0.13$ & $1.68 \pm 0.19$ & $P=0.9084 ;$ n.s.; t-test \\
\hline
\end{tabular}

\section{O-Maze}

As compared to akt2 $2^{+/+}$mice, akt2\% mice showed significantly less protected and unprotected head dips in the O-Maze test (Fig. 3B, C). The akt2\% mice visited the open arms less frequently and travelled a shorter distance there as well. Also the time spent in the open arms was significantly decreased in $a k t 2^{\%}$ mice (Fig. 3D-F). Consequently, the number of 
A

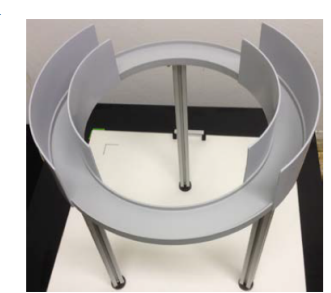

$\mathrm{D}$

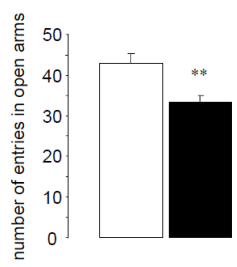

G

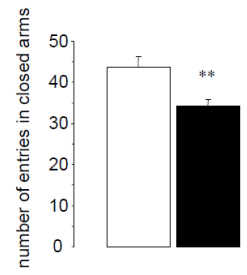

B

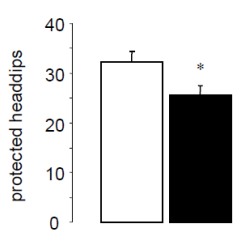

E

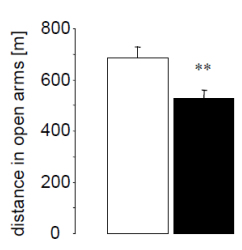

$\mathrm{H}$

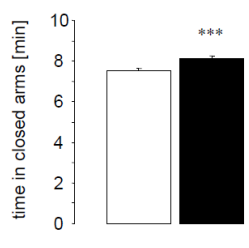

(C) 2013 S. Karger AG, Basel

www.karger.com/cpb

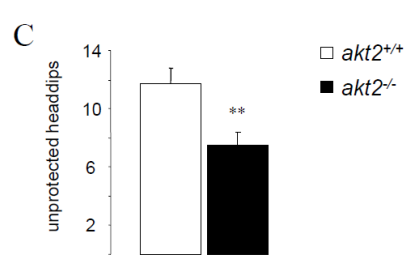

F
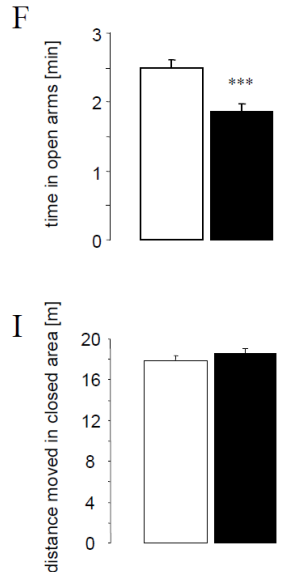

Fig. 3. Analysis of behavior in the O-Maze. A: Layout of the O-Maze. B: Number of protected headdips. C: Number of unprotected headdips. D: Number visits to the open arms. E: Distance travelled in the open arms of the maze. F: Time spent in the open arms of the maze. G: Number of entries into the closed arms. H: Time spent in the closed arms of the maze. I: Distance travelled in the closed arms of the maze.

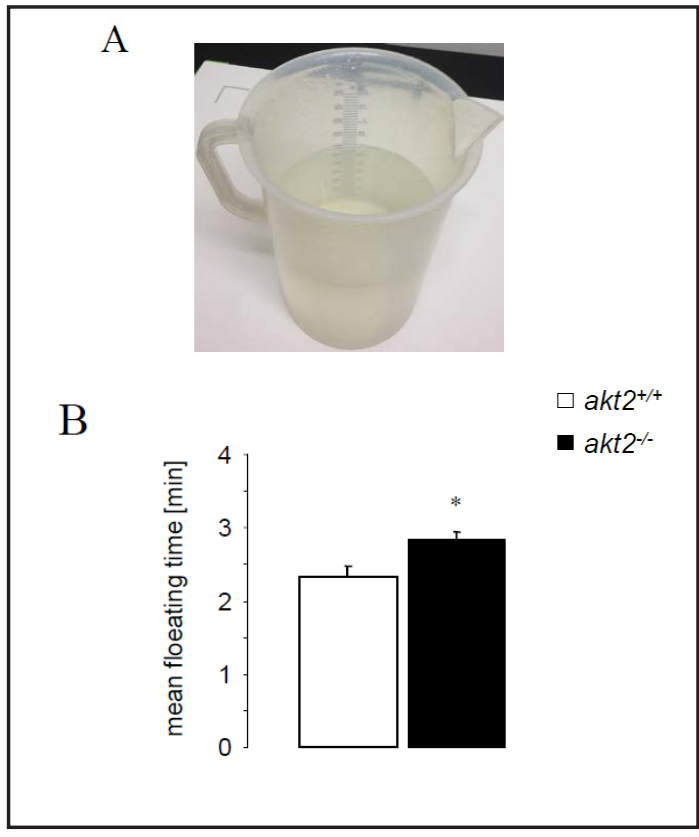

Fig. 4. Analysis of behavior in the Forced Swimming Test. A: Photograph of the Forced Swimming Test arena. B: Average floating time.
A
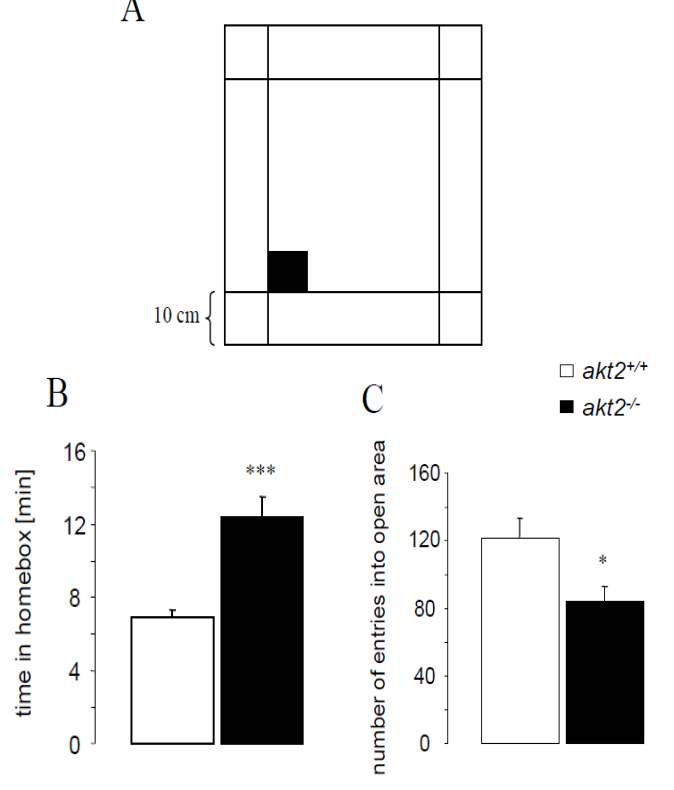

Fig. 5. Analysis of behavior in the Emergence Test. A: Layout of the Emergence Test arena. B: Time spent in the homebox. C: Number of visits of the open area.

entries into the protected arms was less in $a k t 2 \%$ mice (Fig. 3G). Despite the fact, that they spent more time in the closed area (Fig. $3 \mathrm{H}$ ), the distance covered there by the akt2\% mice was almost the same as the distance travelled by $a k t 2^{+/+}$mice (Fig. 3I) 


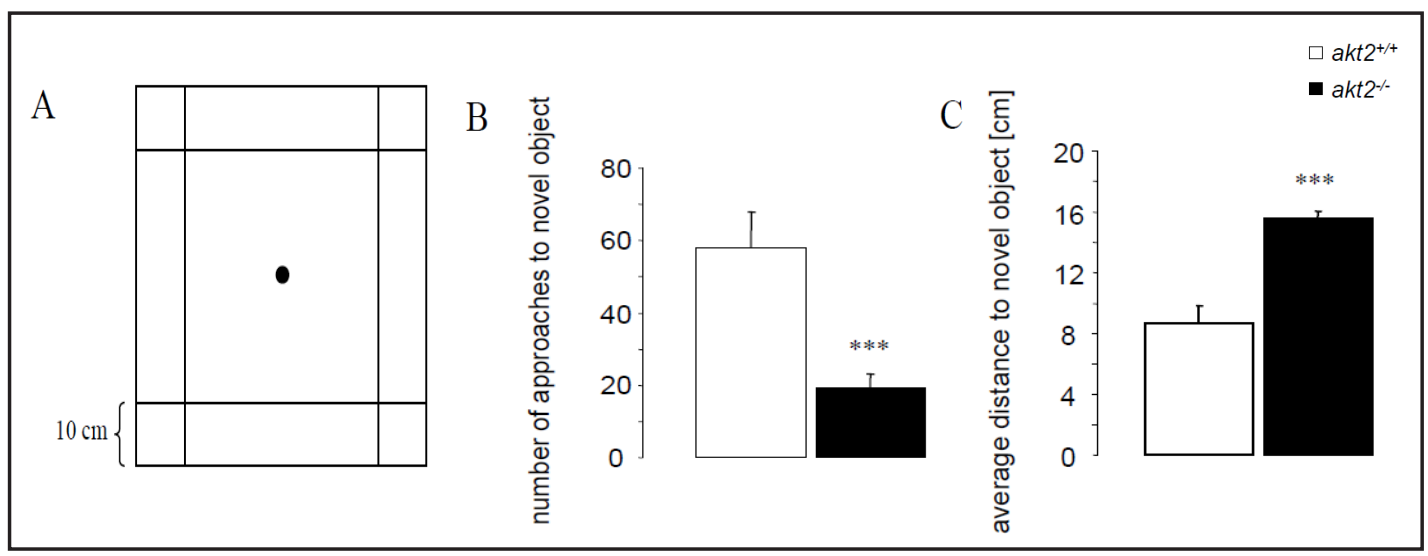

Fig. 6. Analysis of behavior in the Novel Object Test. A: Layout of the O-Maze. B: Number of approaches to the novel object. C: Average distance to the novel object.

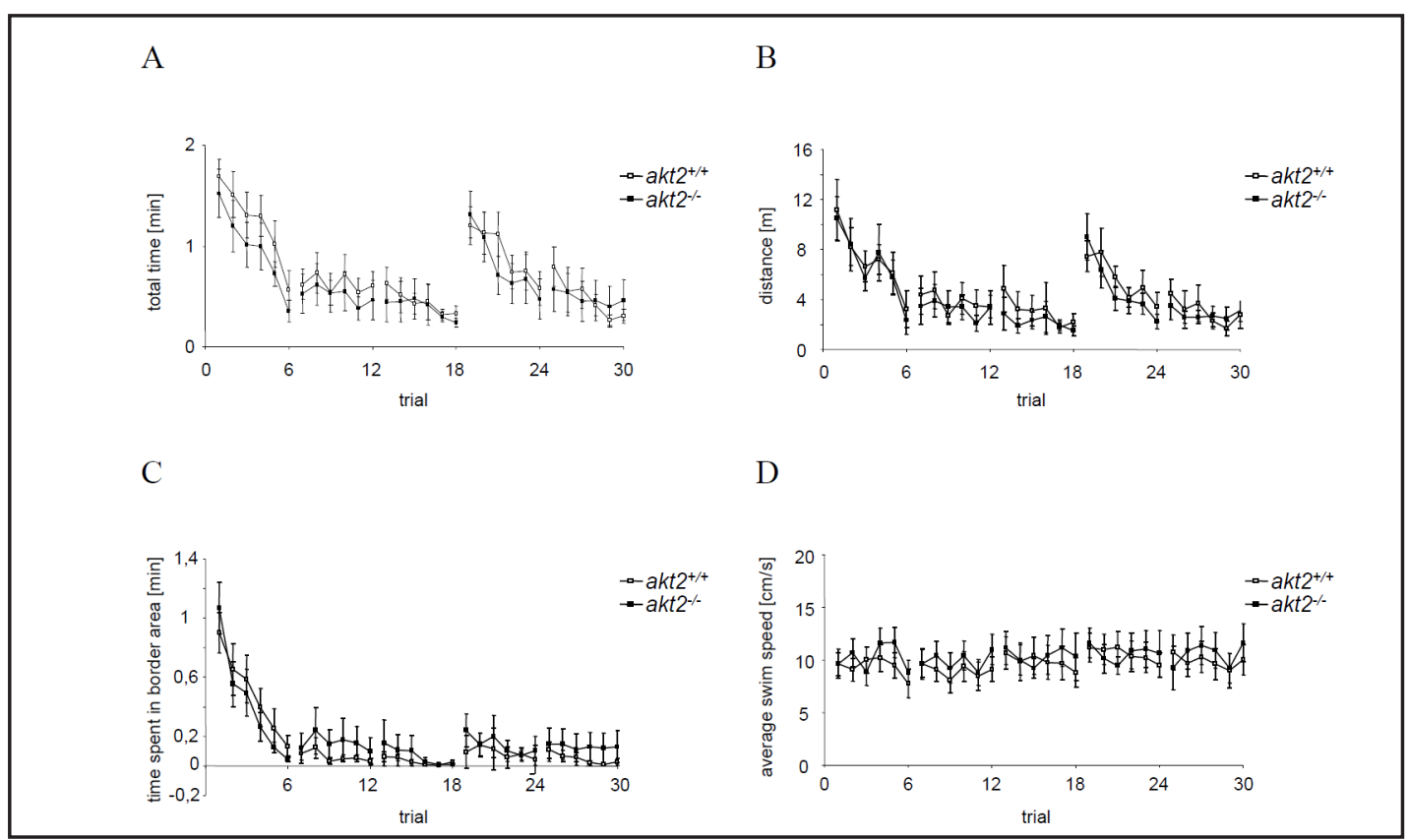

Fig. 7. Analysis of behavior in the Morris Water Maze. A: Time to find the hidden platform. B: Distance travelled until completion of the task. C: Time spent in the border area of the maze. D: Average swim velocity during the task.

\section{Forced Swimming Test}

In the Forced Swimming Test the $a k t 2 \%$ mice spent significantly more time floating on the surface of the water than the $a k t 2^{+/+}$mice (Fig. 4B).

\section{Emergence Test}

During the Emergence Test akt2\% mice spent significantly more time in the homebox than the $a k t 2^{+/+}$mice (Fig. 5B). The number of visits to the open area was also decreased in akt2\% mice (Fig. 5C).

\section{Novel Object Test}

In the Novel Object Test the curiosity of the mice was tested. akt $\%$ mice examined the novel object less often and kept a larger distance to the novel object over the whole time period than the $a k t 2^{+/+}$mice (Fig. 6B, C). 


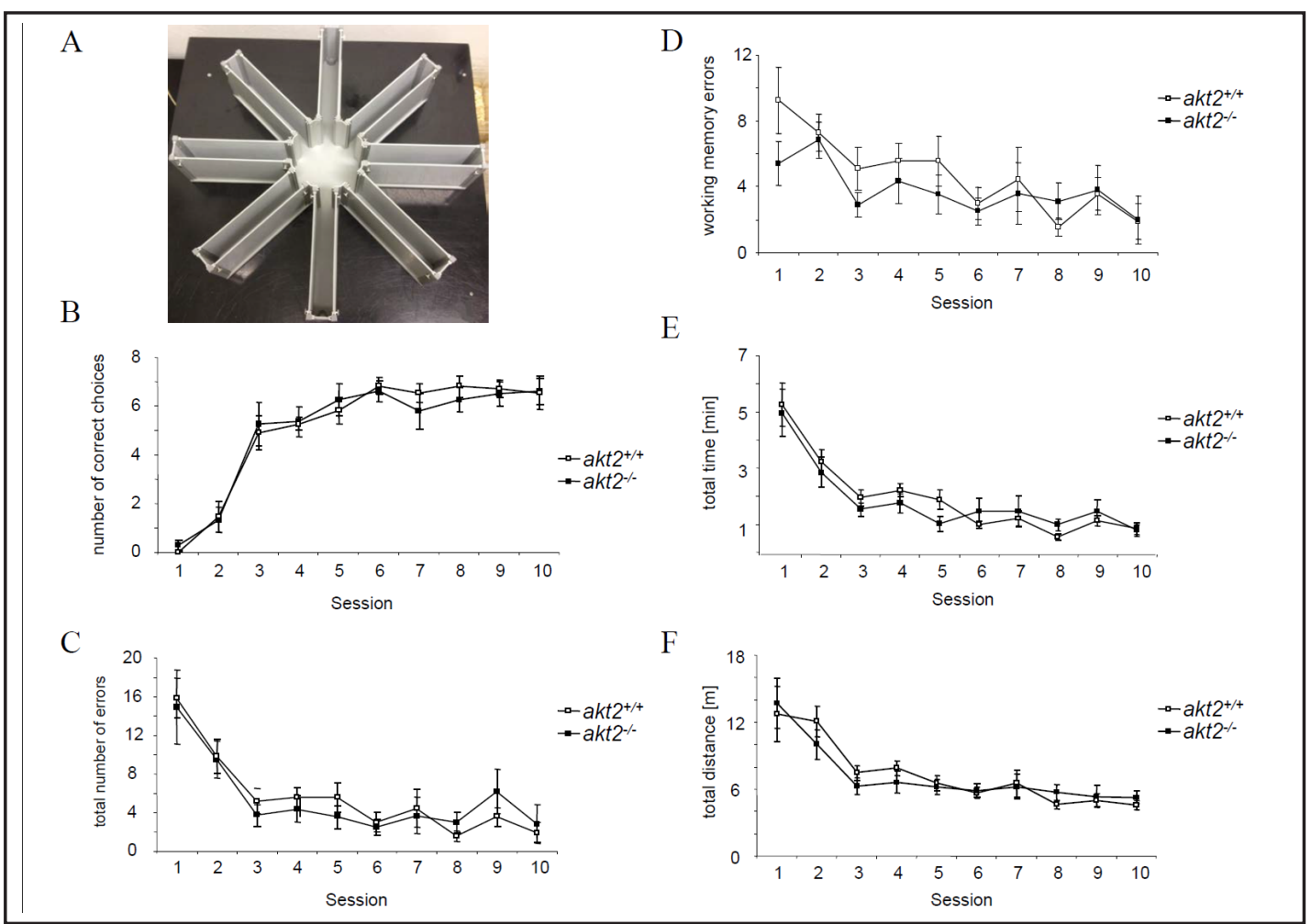

Fig. 8. Analysis of behavior in the 8-arm Radial Maze. A: Photograph of the 8-arm radial maze arena. B: Number of correct choices until the first error occurs. C: Total number of errors. D: Number of working memory errors. E: Time to complete the task by collecting all baits. F: Distance travelled until all baits were collected.

\section{Morris Water Maze}

The performance of $a k t 2 \%$ mice in the Morris Water Maze was not different from $a k t 2^{+/+}$ mice. Both groups showed that they were equally fast in learning and orientation as shown by decreasing time to complete the trials (Fig. 7A), shorter distances to reach the platform (Fig. 7B) and less time exploring the border area (Fig. 7C). The mice also acquired fast to the new challenge after the platform was moved to the opposite quadrant of the tank (trial 19-30). The swimming velocity remained approximately the same during all trials (Fig. 7D).

\section{Radial Maze}

Again in the radial maze $a k t 2^{+/+}$mice and $a k t 2^{+/+}$mice did not show any significant differences. The number of correct choices until the first error occurred increased (Fig. 8B) showing the learning effect in both groups. Also the number of total errors (Fig. 8C) and working memory errors (Fig. 8D) dropped in both groups during the sessions. The mice needed less time to collect the hidden baits (Fig. 8E) and also had to travel shorter distances (Fig. 8F) to complete the task.

\section{Discussion}

In order to explore the in vivo functional significance of Akt2 in the regulation of behavior, we assessed the performance of Akt2 knockout mice $(A k t 2 \%)$ and C57Bl/6J wild type mice in a place navigation task in the water maze, radial maze and in a battery of forced and free exploration tests.

In the open-field the total distance traveled was decreased in akt2\% mice. akt2\% mice spent more time in the border area and spent significantly increased time in the corners. 
In the dark light box, akt2\% mice spent significantly more time in the hidden area, showed less rearing behavior, a shorter rearing time and a smaller ratio of number/time rearing. In the 0-Maze test, akt2\% mice showed significantly less protected and unprotected head dips, visited the open areas less frequently and travelled a larger distance there as well. In the Forced Swimming Test the akt $\%$ mice spent significantly more time floating on the surface of the water. During the Emergence Test akt2\% mice spent significantly more time in the homebox than the $a k t 2^{+/+}$mice. The number of visits to the open area was also decreased.

In the Novel Object Test the curiosity of akt $\%$ mice was decreased, i.e. akt $2 \%$ mice examined the novel object less often and kept a longer distance to the novel object over the whole time period. In must be considered, however, that the results of the novel object test are affected by the location of the novel object in the center of the open field.

In conclusion we found decreased activity, increased anxiety, increased depressive behavior and less exploratory behavior in akt2\% mice. Increased anxiety was observed in the O-Maze test, the dark light box and in the open field paradigm.

The present data reveal a powerful inhibitory effect of Akt 2 on anxiety and depression. The present study did not address the Akt2 dependent mechanisms accounting for the impact on behavior. In theory, Akt2 could be effective through phosphorylation and thus inhibition of GSK3 [40]. However, inhibition of GSK3 reduces both depression-like and manic-like behavior [41] and transgenic mice overexpressing glycogen synthase kinase 3 beta display hyperactivity and mania [42]. Moreover, mice expressing Akt-resistant GSK3 are hyperactive and curious [19]. Conversely, inhibition of GSK3 beta results in increased anxiety behavior [43]. Thus, disruption of GSK3 phosphorylation and inhibition does not explain the phenotype of the akt2-/- mice.

In view of the known effect of Akt2 on dopamine transporter cell surface expression [37], deranged dopamine transporter activity could in theory contribute to the phenotype of the akt2-/- mice. Both, Akt and GSK3 have been suggested to participate in the regulation of behavior by influencing the monoamine neurotransmitters dopamine and serotonin [44].

The behavioral phenotype of the Akt2 deficient mouse is similar to that of the PDK1 hypomorphic mouse, which displayed enhanced anxiety paralleled by significantly decreased GABA, taurine and serotonin concentrations in the amygdala [20]. As anxietyrelated behavior is often connected with a clear bias towards passive coping styles, the neophobia observed in akt2-/- mice might predispose these animals to anxious behavior.

The reduced locomotion and increased floating in the forced swimming test of Akt2 knockout mice could be linked to a depression-like state in rodents, which could be attributed to disturbed BDNF and PI3K signaling via Akt2. It is tempting to speculate that Akt2 exerts some antidepressant effects and that reduced stimulation of Akt2 may lead to depressive disorders. If so, the present observations may help to resolve the apparent discrepancy on the role of BDNF in the pathophysiology of major depression [45].

Taken together, our results suggest an involvement of Akt2 in anxiety and depressive behavior in mice and identify Akt2 as a potential therapeutic target for the treatment and prevention of anxiety disorders and depression. Future studies are required to delineate the Akt2 sensitive mechanisms accounting for this powerful effect of Akt2 on behavior.

\section{Conflict of Interest}

All contributing authors declare no conflict of interest.

\section{Acknowledgements}

This work was supported by the DFG, Deutsche Forschungsgemeinschaft (LA 2694/1-2). 
Leibrock et al.: Akt2 Impacts on Anxiety and Depression

\section{References}

,

$>2$

$>3$

-4 Lang UE, Hellweg R, Gallinat J: Bdnf serum concentrations in healthy volunteers are associated with depression-related personality traits. Neuropsychopharmacology 2004;29:795-798.

$>5$ Lang UE, Hellweg R, Gallinat J: Association of bdnf serum concentrations with central serotonergic activity: Evidence from auditory signal processing. Neuropsychopharmacology 2005;30:1148-1153.

$>6$ Lang UE, Hellweg R, Kalus P, Bajbouj M, Lenzen KP, Sander T, Kunz D, Gallinat J: Association of a functional bdnf polymorphism and anxiety-related personality traits. Psychopharmacology (Berl) 2005;180:95-99.

7 Duman RS, Monteggia LM: A neurotrophic model for stress-related mood disorders. Biol Psychiatry 2006;59:1116-1127.

8 Deuschle M, Gilles M, Scharnholz B, Lederbogen F, Lang UE, Hellweg R: Changes of serum concentrations of brain-derived neurotrophic factor (bdnf) during treatment with venlafaxine and mirtazapine: Role of medication and response to treatment. Pharmacopsychiatry 2013;46:54-58.

9 Ricken R, Adli M, Lange C, Krusche E, Stamm T, Koehler S, Nase S, Bschor T, Richter C, Steinacher B, Heinz A, Rapp M, Borgwardt S, Hellweg R, Lang U: Reduced bdnf serum concentrations in acute depressive patients increase during lithium augmentation of antidepressants. J Clin Psychopharmacol 2013; in press.

10 Kobayashi T, Cohen P: Activation of serum- and glucocorticoid-regulated protein kinase by agonists that activate phosphatidylinositide 3-kinase is mediated by 3-phosphoinositide-dependent protein kinase-1 (pdk1) and pdk2. Biochem J 1999;339:319-328.

-11 Shi HS, Zhu WL, Liu JF, Luo YX, Si JJ, Wang SJ, Xue YX, Ding ZB, Shi J, Lu L: Pi3k/akt signaling pathway in the basolateral amygdala mediates the rapid antidepressant-like effects of trefoil factor 3. Neuropsychopharmacology 2012;37:2671-2683.

12 Budni J, Lobato KR, Binfare RW, Freitas AE, Costa AP, Martin-de-Saavedra MD, Leal RB, Lopez MG, Rodrigues AL: Involvement of pi3k, gsk-3beta and ppargamma in the antidepressant-like effect of folic acid in the forced swimming test in mice. J Psychopharmacol 2012;26:714-723.

$>13$ Aubry JM, Schwald M, Ballmann E, Karege F: Early effects of mood stabilizers on the akt/gsk-3beta signaling pathway and on cell survival and proliferation. Psychopharmacology (Berl) 2009;205:419-429.

$>14$ Gould TD, Manji HK: Glycogen synthase kinase-3: A putative molecular target for lithium mimetic drugs. Neuropsychopharmacology 2005;30:1223-1237.

15 Klein PS, Melton DA: A molecular mechanism for the effect of lithium on development. Proc Natl Acad Sci USA 1996;93:8455-8459.

16 Lu XH, Dwyer DS: Second-generation antipsychotic drugs, olanzapine, quetiapine, and clozapine enhance neurite outgrowth in pc12 cells via pi3k/akt, erk, and pertussis toxin-sensitive pathways. J Mol Neurosci 2005;27:43-64.

17 Zhang X, Mi J, Wetsel WC, Davidson C, Xiong X, Chen Q, Ellinwood EH, Lee TH: Pi3 kinase is involved in cocaine behavioral sensitization and its reversal with brain area specificity. Biochem Biophys Res Commun 2006;340:1144-1150.

18 Pattwell SS, Bath KG, Casey BJ, Ninan I, Lee FS: Selective early-acquired fear memories undergo temporary suppression during adolescence. Proc Natl Acad Sci USA 2011;108:1182-1187.

19 Ackermann TF, Kempe DS, Lang F, Lang UE: Hyperactivity and enhanced curiosity of mice expressing pkb/ sgk-resistant glycogen synthase kinase-3 (gsk-3). Cell Physiol Biochem 2010;25:775-786.

20 Ackermann TF, Hortnagl H, Wolfer DP, Colacicco G, Sohr R, Lang F, Hellweg R, Lang UE: Phosphatidylinositide dependent kinase deficiency increases anxiety and decreases gaba and serotonin abundance in the amygdala. Cell Physiol Biochem 2008;22:735-744.

-21 Diez H, Garrido JJ, Wandosell F: Specific roles of akt iso forms in apoptosis and axon growth regulation in neurons. PLoS One 2012;7:e32715.

-22 Cho H, Thorvaldsen JL, Chu Q, Feng F, Birnbaum MJ: Akt1/pkbalpha is required for normal growth but dispensable for maintenance of glucose homeostasis in mice. J Biol Chem 2001;276:38349-38352.

23 Yang ZZ, Tschopp 0, Hemmings-Mieszczak M, Feng J, Brodbeck D, Perentes E, Hemmings BA: Protein kinase b alpha/akt1 regulates placental development and fetal growth. J Biol Chem 2003;278:32124-32131. 
Leibrock et al.: Akt2 Impacts on Anxiety and Depression

24 Carter CJ: Eif2b and oligodendrocyte survival: Where nature and nurture meet in bipolar disorder and schizophrenia? Schizophr Bull 2007;33:1343-1353.

25 Carter CJ: Multiple genes and factors associated with bipolar disorder converge on growth factor and stress activated kinase pathways controlling translation initiation: Implications for oligodendrocyte viability. Neurochem Int 2007;50:461-490.

-26 Maier W, Zobel A, Kuhn KU: Clinical impact of recently detected susceptibility genes for schizophrenia. Dialogues Clin Neurosci 2006;8:79-84.

27 Detera-Wadleigh SD: Lithium-related genetics of bipolar disorder. Ann Med 2001;33:272-285.

28 Easton RM, Cho H, Roovers K, Shineman DW, Mizrahi M, Forman MS, Lee VM, Szabolcs M, de Jong R, Oltersdorf T, Ludwig T, Efstratiadis A, Birnbaum MJ: Role for akt3/protein kinase bgamma in attainment of normal brain size. Mol Cell Biol 2005;25:1869-1878.

29 Tschopp 0, Yang ZZ, Brodbeck D, Dummler BA, Hemmings-Mieszczak M, Watanabe T, Michaelis T, Frahm J, Hemmings BA: Essential role of protein kinase b gamma (pkb gamma/akt3) in postnatal brain development but not in glucose homeostasis. Development 2005;132:2943-2954.

30 Poduri A, Evrony GD, Cai X, Elhosary PC, Beroukhim R, Lehtinen MK, Hills LB, Heinzen EL, Hill A, Hill RS, Barry BJ, Bourgeois BF, Riviello JJ, Barkovich AJ, Black PM, Ligon KL, Walsh CA: Somatic activation of akt3 causes hemispheric developmental brain malformations. Neuron 2012;74:41-48.

-31 Baek ST, Gibbs EM, Gleeson JG, Mathern GW: Hemimegalencephaly, a paradigm for somatic postzygotic neurodevelopmental disorders. Curr Opin Neurol 2013;26:122-127.

-32 Sarnat H, Flores-Sarnat L, Crino P, Hader W, Bello-Espinosa L: Hemimegalencephaly: Foetal tauopathy with mtor hyperactivation and neuronal lipidosis. Folia Neuropathol 2012;50:330-345.

-33 Cho H, Mu J, Kim JK, Thorvaldsen JL, Chu Q, Crenshaw EB, III, Kaestner KH, Bartolomei MS, Shulman GI, Birnbaum MJ: Insulin resistance and a diabetes mellitus-like syndrome in mice lacking the protein kinase akt2 (pkb beta). Science 2001;292:1728-1731.

-34 Garofalo RS, Orena SJ, Rafidi K, Torchia AJ, Stock JL, Hildebrandt AL, Coskran T, Black SC, Brees DJ, Wicks JR, McNeish JD, Coleman KG: Severe diabetes, age-dependent loss of adipose tissue, and mild growth deficiency in mice lacking akt2/pkb beta. J Clin Invest 2003;112:197-208.

35 Li G, Anderson RE, Tomita H, Adler R, Liu X, Zack DJ, Rajala RV: Nonredundant role of akt2 for neuroprotection of rod photoreceptor cells from light-induced cell death. J Neurosci 2007;27:203-211.

-36 Vojtek AB, Taylor J, DeRuiter SL, Yu JY, Figueroa C, Kwok RP, Turner DL: Akt regulates basic helix-loop-helix transcription factor-coactivator complex formation and activity during neuronal differentiation. Mol Cell Biol 2003;23:4417-4427.

-37 Speed NK, Matthies HJ, Kennedy JP, Vaughan RA, Javitch JA, Russo SJ, Lindsley CW, Niswender K, Galli A: Akt-dependent and isoform-specific regulation of dopamine transporter cell surface expression. ACS Chem Neurosci 2010;1:476-481.

38 Dulawa SC, Grandy DK, Low MJ, Paulus MP, Geyer MA: Dopamine d4 receptor-knock-out mice exhibit reduced exploration of novel stimuli. J Neurosci 1999;19:9550-9556.

-39 Mohajeri MH, Madani R, Saini K, Lipp HP, Nitsch RM, Wolfer DP: The impact of genetic background on neurodegeneration and behavior in seizured mice. Genes Brain Behav 2004;3:228-239.

40 Cross DA, Alessi DR, Cohen P, Andjelkovich M, Hemmings BA: Inhibition of glycogen synthase kinase-3 by insulin mediated by protein kinase b. Nature 1995;378:785-789.

41 Jope RS: Glycogen synthase kinase-3 in the etiology and treatment of mood disorders. Front Mol Neurosci 2011;4:16.

42 Prickaerts J, Moechars D, Cryns K, Lenaerts I, van Craenendonck H, Goris I, Daneels G, Bouwknecht JA, Steckler T: Transgenic mice overexpressing glycogen synthase kinase 3beta: A putative model of hyperactivity and mania. J Neurosci 2006;26:9022-9029.

43 Mines MA, Yuskaitis CJ, King MK, Beurel E, Jope RS: Gsk3 influences social preference and anxietyrelated behaviors during social interaction in a mouse model of fragile x syndrome and autism. PLoS One 2010;5:e9706.

44 Beaulieu JM: A role for akt and glycogen synthase kinase-3 as integrators of dopamine and serotonin neurotransmission in mental health. J Psychiatry Neurosci 2012;37:7-16.

45 Lang UE, Jockers-Scherubl MC, Hellweg R: State of the art of the neurotrophin hypothesis in psychiatric disorders: Implications and limitations. J Neural Transm 2004;111:387-411. 